\title{
CORPUS Corpus
}

Archivos virtuales de la alteridad americana

Vol 6, No 2 | 2016

Julio / Diciembre 2016

Reseña de Las poblaciones indígenas en la conformación de las naciones y los Estados en la América Latina decimonónica, coordinado y editado por Ingrid de Jong y Antonio Escobar Ohmstede, México, Centro de Estudios Históricos, 2016, 478 páginas

Judith Farberman

\section{OpenEdition}

Journals

Electronic version

URL: http://journals.openedition.org/corpusarchivos/1636

DOI: 10.4000/corpusarchivos. 1636

ISSN: 1853-8037

Publisher

Diego Escolar

Electronic reference

Judith Farberman, « Reseña de Las poblaciones indígenas en la conformación de las naciones y los

Estados en la América Latina decimonónica, coordinado y editado por Ingrid de Jong y Antonio Escobar Ohmstede, México, Centro de Estudios Históricos, 2016, 478 páginas », Corpus [En línea], Vol 6, No 2 | 2016, Publicado el 21 diciembre 2016, consultado el 30 abril 2019. URL : http:// journals.openedition.org/corpusarchivos/1636 ; DOI : 10.4000/corpusarchivos.1636

This text was automatically generated on 30 April 2019

Licencia Creative Commons: Atribución-NoComercial 2.5 Argentina (CC BY-NC 2.5 AR) 
Reseña de Las poblaciones indígenas en la conformación de las naciones y los Estados en la América Latina decimonónica, coordinado y editado por Ingrid de Jong y Antonio Escobar Ohmstede, México, Centro de Estudios Históricos, 2016, 478 páginas

Judith Farberman

1 El libro que coordinan Antonio Escobar e Ingrid de Jong contiene diez artículos y una introducción de los autores. Ocho artículos son comparativos -en seis casos México (o una región / estado mexicano) es uno de los términos de comparación, dos consideran el territorio fronterizo argentino chileno- mientras que los dos restantes se apartan de este tipo análisis. Cierta sobrerrepresentación de México, una presencia más débil de los estados andinos y la inclusión de dos textos sobre Brasil -país habitualmente dejado de lado en las antologías y aislado como caso de estudio- pueden advertirse de una veloz mirada al índice del libro. Por otra parte, todos los trabajos se intersectan en el siglo XIX con desarrollos hacia atrás - la transición entre colonia y república- y proyecciones hacia adelante - la construcción del Estado, las reformas liberales, el ocaso de las fronteras-, otorgando coherencia al volumen colectivo.

2 Los cinco primeros trabajos (Antonio Escobar Ohmstede, María Regina Celestino de Almeida, Vania María Losada Moreira, María Dolores Palomo Infante y Romana Falcón) tienen en México uno de los términos de la comparación. Sin embargo, estas comparaciones enfatizan más en las semejanzas que en las diferencias. En rigor, la 
estrategia comparativa es más que nada un válido intento de contextualización, basado más en el examen bibliográfico que en la investigación de primera mano del caso que sirve de control.

Quizás por seguir muy de cerca la agenda de investigación mexicana, la primera mitad del libro muestra una notable unidad. Seis cuestiones principales se entrecruzan en los artículos:

4 La ciudadanización de los indígenas y los hitos de su construcción. Vale decir, el socavamiento del estatus diferencial del "indio colonial" en beneficio de la homogeneización jurídica.

5 La representación política indígena en este contexto y el acceso a la justicia con énfasis en el papel de los ayuntamientos.

6 La transición entre el pueblo de indios colonial y el ordenamiento municipal republicano.

7 La reformulación de la "indianidad" en el contexto de la ladinización de los pueblos y municipalidades.

8 La tierra, las leyes agrarias y las resistencias o participación indígenas en el tránsito hacia el individualismo agrario.

El mercado de trabajo en el contexto de avance de la agricultura de exportación.

10 Tenemos aquí, por tanto, diversas dimensiones de un mismo problema. Los textos nos muestran cómo el estamento colonial de "indio" - categoría más jurídica que étnica en la Colonia tardía - a la vez que fijaba una serie de obligaciones concedía como contrapartida algunos derechos. Estos, a su vez, se acompañaban de instrumentos e instituciones que hacían posible su defensa. Hasta principios del siglo XIX, no obstante los intentos borbónicos de reformar el sistema, la naturaleza corporativa de los pueblos fue sinónimo de amparo legal. Por ello, las presiones sobre las tierras colectivas se legitimaban a partir de la extinción de los "indios puros" y de la defensa de la igualdad jurídica. Paradójicamente, no obstante su posición subordinada derivada del mismo derecho de conquista, los indígenas contaban con mejores posibilidades para subsistir y defenderse durante la Colonia que en la república. El antiguo régimen y sus corporaciones les cabían mejor que una igualdad que apenas si otorgaba una ciudadanía subalternizada.

11 De un modo $u$ otro, los cinco primeros artículos giran en torno de estos grandes temas. Con lo cual, es posible destacar también otros horizontes comunes desde los cuales se plantean los problemas de investigación. Por ejemplo, el horizonte remoto de la república de indios, que el Estado intenta destruir y los antiguos tributarios revitalizar. Por ejemplo, más presente aún, el horizonte borbónico con sus antecedentes liberales y también Cádiz -cuyos "verdaderos efectos" pueden ser cuestionados pero que aparece siempre como referencia para estas regiones-. Las revoluciones de independencia y las reformas liberales, más precoces en México, algo más tardías en las otras naciones consideradas, son los restantes hitos que articulan los trabajos.

Reseñaré brevemente los principales aportes de los artículos y algunos de los cruces que pueden detectarse entre ellos. Antonio Escobar Ohmstede se ocupa de las ciudadanías diferenciadas en México, Bolivia y Colombia, desde las revoluciones de independencia hasta 1821, con una necesaria mirada hacia las estructuras coloniales sacudidas en la transición. El autor nos muestra la conformación de "ciudadanías indígenas diferenciadas", partiendo del supuesto de que Cádiz representa en el proceso político una ruptura más simbólica que un impacto real. Una segunda cuestión importante es la de la 
ciudadanización como extensión de la vecindad colonial, proceso que se verifica más en el plano de las nuevas obligaciones que en el de los derechos que se adquieren.

María Regina Celestino de Almeida piensa Brasil y México desde escalas más pequeñas. Recupera el caso de los pueblos de indios coloniales y sus equivalentes aldeamentos de las ciudades de México y Río de Janeiro respectivamente, a partir de las reformas borbónicas y pombalinas y hasta mediados del siglo XIX. En estos casos, el problema de la construcción de la ciudadanía -cuyos inicios se rastrean ya tempranamente a fines del siglo XVII y aún antes para Brasil- se enfoca asociado con el de la pérdida de la base territorial y del retroceso en la representación política indígena. Se destaca también, para ambos contextos, el abordaje de la defensa de las tierras acudiendo a la etnicidad como potente argumento para preservarlas. Sin embargo, lo interesante es que la retórica de la etnicidad se vale de la categoría colonial o, más bien, se atrinchera en ella. "Ser indio", demuestra Celestino de Almeida, permite defender mejores condiciones o, al menos, no perderlo todo. Un nuevo problema se pone así en consideración: el de las identidades indias construidas por una política colonial que, mucho tiempo antes, había reducido a la unidad múltiples identidades étnicas anteriores.

Vania Losada Moreira continúa donde Celestino de Almeida concluye su artículo, concentrándose en México y Brasil en la década de 1850 y abordando dos fenómenos encadenados. Por un lado, la cuestión de la ciudadanía que reviste en los dos espacios la modalidad de extensión de la vecindad, ya comentada por Antonio Escobar Ohmstede. Un dato de especial interés para el caso brasileño, acaso soslayado por una historiografía que ha tendido a privilegiar las continuidades en las políticas de las etapas colonial e imperial, es la "reproposición" de una estructura similar a la de los antiguos aldeamentos para los "indios bravos". Estos aldeamentos coloniales habían conocido una suerte muy parecida a la de los pueblos de indios del imperio español: sus límites fueron rebasados por una población heterogénea que, en no pocos casos, había terminado por gestionar las tierras y el gobierno. A mediados del siglo XIX, a la par que se desprestigiaba en la cruzada anticorporativa liberal, el aldeamento era propuesto como solución para nacionalizar a quienes no fueran todavía brasileños, vale decir, a los grupos soberanos. La segunda parte del trabajo de Losada Moreira se ocupa más específicamente de las tierras, señalando una diferencia sustantiva con el caso mexicano. En Brasil, la ley de tierras se cruza con la necesidad de reemplazar el trabajo esclavo y su único blanco efectivo es la tierra indígena: no hay corporaciones religiosas afectadas por la política liberal y la difuminación del estatus de indio, como en otras regiones, alienta la desarticulación de las estructuras supuestamente creadas para ellos.

María Dolores Palomo Infante se aproxima al enfoque comparativo considerando una misma región colonial luego fragmentada en estados nacionales separados: Chiapas y El Salvador. Su objeto de estudio privilegiado es el ayuntamiento en sus funciones de administración de justicia y agente de privatización de tierras en la segunda mitad del siglo XIX. El fenómeno común a los dos espacios -analizado también en los aldeamentos brasileños, aunque no reciban ese nombre- $\mathrm{y}$ a buena parte de las antiguas corporaciones iberoamericanas es el de la ladinización, entendido como asentamiento en los antiguos pueblos de gentes no indias. Municipalización y ladinización son procesos paralelos y espontáneos en Chiapas, mientras que en El Salvador es el desarrollo del añil y de la caña de azúcar el que parece propiciarlo. El resultado es la progresiva invisibilización del componente indígena de los pueblos que solo contarán con los ayuntamientos -mediados por los principales ancianos- como canales de acceso a la justicia. Un punto importante 
de este trabajo, común a otras regiones, es que en este avance del individualismo agrario que acelera el auge de los cultivos comerciales también hay indígenas comprando propiedades. Mientras en El Salvador el avance arrollador del Estado liberal coexiste con la disputa intracomunitaria, en Chiapas, el asunto parece menos catastrófico gracias al manejo de los "enredos y sutilezas del derecho" que marca una apropiación de los discursos dominantes por parte de los indígenas. Por tanto, el texto de Palomo Infante nos permite completar los tránsitos que hemos ido siguiendo en otros artículos del volumen: del pueblo de indios al municipio / de súdbito a ciudadano vía expansión de la vecindad. Y ahora, como fenómeno concomitante, la ladinización.

El trabajo de Romana Falcón, aborda las problemáticas que fuimos desgranando a partir del papel mediador de las jefaturas políticas de México y Guatemala en la segunda mitad del siglo XIX. Una vez más nos encontramos con antecedentes borbónicos, nuevas precisiones y aditamentos que provienen de Cádiz y actuaciones decisivas en la era liberal. Estos punteros, terratenientes, cabezas de vastas clientelas cumplen con funciones variadas: desde la mentada obligación de los funcionarios coloniales de cuidar la "policía" de los indígenas hasta las necesidades más nuevas de proveer trabajadores para las plantaciones de café. Así pues, se reeditan, a mediados del siglo XIX, las tensiones de la era de la república de los indios: cómo conseguir trabajadores sin destruir la base material de los pueblos. Todo esto en el marco de un sistema de trabajo forzado de raíces coloniales. La diferencia fundamental con la primera Colonia, aunque tiene antecedentes borbónicos, es la promoción del contacto con los ladinos. Ahora bien, como muestra Falcón, en la medida en que las jefaturas políticas funcionan como bisagras, será allí donde los indígenas se labrarán su espacio de negociación. Como mediadores, los jefes políticos no logran conformar a nadie, ni a los indígenas (a los que no protegen) ni a las fincas (que no obtienen los trabajadores que necesitan). En México la situación es más o menos similar aunque las respuestas sociales son contradictorias y ello, apunta la autora, obedece a las mismas contradicciones de base de la legislación liberal en la que, a pesar de todo, los actores colectivos podían como tales seguir litigando en los tribunales. En este contexto, la mediación de los jefes políticos no siempre será en beneficio de notables y ricos. Un aporte que agrega este artículo a la compilación es el dar cuenta de las diferencias regionales que afectan a México: Chiapas, muestra Falcón, va a contrapelo del Estado nacional.

Hasta aquí, la primera parte del libro. Los cinco artículos que componen la segunda nos trasladan a otras geografías, quizás más periféricas, y también a otras cuestiones. La balanza de la comparación se inclina desde México hacia la actual Argentina y a sus fronteras meridionales. De consecuencia, los avances estatales sobre las sociedades indígenas se operan sobre regiones interiores, aisladas o marginales. También el marco temporal se corre respecto de la primera parte para moverse hacia finales del siglo XIX y nuevos dispositivos - como la educación y las relaciones diplomáticas- entran en consideración. Como anticipamos al comienzo, los trabajos de Lorena Rodríguez y Nuria Sala i Vila escapan a esta regla general, y de ellos nos ocuparemos en primer lugar.

Nuria Sala i Vila se ocupa de la Hoya del Madre de Dios, un territorio en disputa entre Perú, Brasil y Bolivia en los años de auge de la explotación cauchera. Es un ejemplo de cómo un ciclo productivo "construye una región" dislocando en simultáneo toda una trama de articulaciones interétnicas sostenidas por intercambios seculares, conflictos por territorios y alianzas políticas. Entre mediados del siglo XIX y 1920, la valorización del caucho significará el desplazamiento, reclutamiento laboral y liso y llano exterminio de 
los indígenas de la zona. También hiperfragmentación de los grupos con los cuales los empresarios entran en contacto. Así es que, en el mejor momento del ciclo cauchero y combinando la coerción y el paternalismo, los diversos grupos étnicos quedan asociados a las especializaciones laborales de las plantaciones. Cuando las empresas se retiran una vez agotado el ciclo del caucho, el legado será un "territorio étnico transformado en islas discontinuas" (Salas i Vila 2016, p. 460). Es un estudio de caso ejemplar en el que la acción de los caucheros es mucho más visible que la de las autoridades estatales de Bolivia, Brasil y Perú que poco se ocupan de aquellos enclaves.

19 El artículo de Lorena Rodríguez es el que quizás mejor dialoga con la primera parte del libro. Lo hace a partir de algunas semejanzas - su objeto de investigación son dos pueblos de indios tucumanos que funcionan como unidad, Colalao y Tolombón, luego de las revoluciones de independencia- pero también desde los contrastes -la diferencia de escala con las corporaciones mexicanas así como la precariedad de su estructura institucional es ostensible-. ¿Hasta qué punto se parecen los "apoderados" de Colalao y Tolombón, mediadores de la comunidad en sede judicial y disputados miembros de la misma a los jefes políticos mexicanos y guatemaltecos estudiados por Romana Falcón? Una obvia diferencia de escala puede adivinarse entre unos y otros: los personajes que nos presenta Rodríguez parecen humildes en comparación con los poderosos terratenientes de los pueblos del norte y Centroamérica. Y sin embargo, en los dos casos el problema de la representación asociado al de las redefiniciones comunitarias está presente. De manera muy razonable, Rodríguez hipotetiza que son los límites de la comunidad de Colalao y Tolombón los que se discuten en tiempos republicanos. Una vez desdibujada la categoría de "indio" ¿quién es el advenedizo? ¿Qué atributos definen la membresía a la comunidad? Por último, los tres artículos que completan el libro tienen como uno de los términos de la comparación la frontera pampeano-patagónica que viene a integrarse al Estado nacional en coincidencia con su consolidación a fines del siglo XIX. Como es sabido, un haz de políticas estatales defensivas y ofensivas terminaron con las sociedades de frontera en coincidencia con la consolidación del Estado nacional argentino. No obstante, el interés de los tres artículos no apunta tanto a la cuestión de las campañas militares como a otros dispositivos y a sus cambios en el tiempo. En rigor, la región que delimitan los artículos de Ingrid de Jong y de Jaime Flores Chávez atravesaba la cordillera y llevaba siglos de complementariedad económica. Aunque De Jong focaliza prioritariamente en los parlamentos indígenas - que considera relevantes aún en el tramo final de la soberanía indígena-, su trabajo recorre un siglo de instancias de articulación entre indígenas de uno y otro lado de los Andes y con sus respectivos Estados nacionales y provinciales. El espacio pampeano -afirma la autora- aparece más conflictivo que el chileno desde el primer momento y los tratados que se consiguen tienen efectos más limitados. Si en Chile la normativización alcanza una cierta consistencia, en la región pampeano-patagónica, especialmente durante el gobierno de Rosas pero también con posterioridad, las relaciones son sobre todo personales. Personales de una y otra parte: como es sabido, ciertos caciques fortalecen sus liderazgos -y sus patrimonios privados- en los primeros momentos de construcción del Estado. De esta manera, el viraje de fines del siglo XIX en Argentina y Chile presenta quizás más analogías que toda la historia anterior de relaciones entre Estado e indígenas.

21 El artículo de Flores Chávez comienza allí donde se detiene el de De Jong. Se muestra aquí cómo el final de las sociedades indígenas soberanas en Argentina y Chile no significa, al menos en un primer momento, la desarticulación económica del complejo cordillerano. 
La historia de los pobladores chilenos de Neuquén permite pensar en la continuidad de algunos de los antiguos circuitos tradicionales en un contexto de nacionalización de indígenas y extranjeros. Por último, articulando directamente con este capítulo, el de Pellegrino Soares se ocupa de los mediadores letrados en poblaciones indígenas mexicanas y argentinas, a fines del siglo XIX. No se trata de espacios, de actores ni de políticas fácilmente comparables. Sin embargo, es interesante en ambos casos la coincidencia en la demanda de las sociedades indígenas para hacerse del instrumento de la escritura. En la necesidad estratégica de apropiarse de la escritura en su propia defensa, se levanta el terreno común en el que prosperaron los cacicazgos indígenas pampeano-patagónicos y sus escribientes así como las comunidades rurales de Oaxaca con sus maestros de primeras letras.

En suma, un volumen colectivo muy recomendable como interesante puesta en común, ejercicio metodológico y con buenas posibilidades de uso didáctico.

\section{AUTHOR}

\section{JUDITH FARBERMAN}

Centro de Estudios en Historia, Cultura y Memoria, Universidad Nacional de Quilmes

y Consejo Nacional de Investigaciones Científicas y Técnicas, Argentina

Correo electrónico : jfarberman@gmail.com 